\title{
Growing Resolve: A ReVIEW OF AN INTRODUCTION TO ENVIRONMENTAL LAW and Policy in Canada, Paul Muldoon, Alastair lucas, Robert Gibson, and PETER PICKFIELd (TORONTO: EMOND MONTGOMERY, 2009)
}

In 2005, commenting on a government review of the main federal toxic substances control legislation, Jason Unger aptly described the general public's usual role in Canadian environmental law: "[They are] left to wander a maze of legislative and non-legislative instruments, each with varying amounts of transparency, to determine whether standards for a particular substance exists, what the standards are, whether they are being met and whether they can take legal action to enforce them."1 Explaining our system of pollution control and resource management law to the general public - where it came from, why it was chosen, in what way it (even remotely) seems rational, how it works, what flaws it has, how to use it, and how one might improve it — is a daunting task indeed. Nevertheless, authors Paul Muldoon, Alastair Lucas, Robert Gibson, and Peter Pickfield ${ }^{2}$ set out in An Introduction to Environmental Law and Policy in Canada ${ }^{3}$ to provide a primer on these issues for interested students and members of the public.

The book is introduced by Anne Mitchell, an executive director with the Canadian Institute for Environmental Law and Policy (CIELAP), ${ }^{4}$ an established Canadian nongovernmental organization (NGO) dedicated to environmental research and education. Her preface draws a parallel between this new book and the 1974 first edition of CIELAP's Environment on Trial, ${ }^{5}$ designed as a guide book to help ordinary citizens better participate in building and improving environmental decisions and laws and encouraging law reform. Readers may well be more familiar with the third edition of Environment on Trial, ${ }^{6}$ which by 1993 had morphed into a 909-page textbook of sufficient detail for use in law schools and by practicing lawyers, albeit several chapters (for example, “How to Wage a Campaign”) remained focused on public participation. An Introduction to Environmental Law and Policy in Canada, at a lean 258 pages, certainly steps back to a simpler and more accessible level of explanation and detail. It is not, however, a citizen's handbook like Environment on Trial in any "how-to" sense; rather it is a general overview, in textbook format, designed to teach the essentials of pollution control and resource management law and policy to non-law students. Thus, while several of the authors, contributors, and publishers have longstanding relationships with CIELAP, An Introduction to Environmental Law and Policy in Canada is not, to my mind, fundamentally the same project as Environment on Trial.

The book is divided into six parts: (1) a description of how the Canadian legal system works; (2) the history and basic structure of environmental law; (3) details on regulatory

Jason Unger, “'Harmony’ in Toxic Substance Regulation Muddles CEPA 1999 Five-Year Review” (2005) 20:1 Environmental Law Centre News Brief 2 at 3.

2 All of the authors are long-standing environmental educators and authors in law and environmental studies, and collaborated on the project with a number of other contributors (lawyers and NGO staff): Maureen Carter-Whitney, Jerry DeMarco, Jessica Ginsburg, David G. Henley, and Theresa McClenaghan.

Paul Muldoon et al., An Introduction to Environmental Law and Policy in Canada (Toronto: Emond Montgomery, 2009).

See online: CIELAP <http://www.cielap.org $>$.

David Estrin \& John Swaigen, eds., Environment on Trial: A Citizen's Guide to Ontario Environmental Law (Toronto: Canadian Environmental Law Research Foundation, 1974).

$6 \quad$ David Estrin \& John Swaigen, Environment on Trial: A Guide to Ontario Environmental Law and Policy, 3d ed. (Toronto: Emond Montgomery, 1993). 
regimes that form the core of our pollution control and sectoral resource management rules; (4) an overview of more integrated approaches such as environmental impact assessment (EIA), planning law, and market-based approaches; (5) a section on using courts, tribunals, and statutory rights; and (6) a look at the direction of environmental laws into the future. It is coupled with a useful glossary, a good index, and a limited list of references; the latter is overly brief and a chapter-by-chapter list of further readings, with additional web sites, would have provided more focus for those interested in more in-depth study of specific topics.

Each part of the book is divided into several chapters, and each chapter has its own miniature outline that provides strong structure. The chapters are not footnoted, however, and while the authors' formidable expertise no doubt gives their statements independent authority, this does limit the usefulness of the book as a reference or research tool, even at a student level.

The five chapters in Part I of the book cover fundamentals: what makes a good law, the scope of environmental law and its key concepts, the relationship between environmental regulation and sectoral resource management regimes, the essentials of federalism, the roles of key players (including municipalities, First Nations, and the courts), and a brief overview of international influences. Organized in a logical fashion, this basic information is, in a few areas, rather too sketchy. For example, the role of regulatory discretion is touched upon quite superficially in chapter 3, yet excessive discretion has been identified quite clearly by numerous experts as one of the core deficiencies of Canadian environmental law. ${ }^{7}$

The next two chapters in Part II of the book cover the basics of environmental law in additional detail. Chapter 6 is a historical overview of the development of environmental law in Canada, coupled with an outline of associated trends that have shaped the direction of our laws, such as the concept of sustainable development. Chapter 7 then goes on to describe the main types of private and public law that are used to address environmental concerns. Again, there are a few fairly important initiatives that receive only passing mention — such as harmonization, deregulation, and some social justice and equity concerns ${ }^{8}-$ although in later chapters the authors do revisit some of these issues in more depth.

Part III of the book marks the beginning of the real heart of the manuscript and it is here that the authors begin to add more depth to their discussion. Chapter 8 is a nicely done overview of the command and control approach at the core of the regulatory process, describing the role of statutes, regulations, approvals, administrative orders, policies, and guidelines. It has a particularly good section on standard setting; like most of the book it is largely descriptive and yet it sets out most of the key debates (such as the role of science) in a matter-of-fact style, without much editorializing. This chapter also has an excellent brief overview of compliance mechanisms - from incentives to prosecutions - with a particularly useful summary of strict enforcement issues, including important concepts such as due diligence. regulatory regime: see David R. Boyd, Unnatural Law: Rethinking Canadian Environmental Law and Policy (Vancouver: UBC Press, 2003) at 228-50. 
Part III continues in chapter 9 with a similar level of examination of the patchwork of rules that make up sectoral natural resource regulation in the areas of fossil fuels, nuclear energy, mining, agriculture, fisheries, pesticides, and biotechnology. While some of these sectors (such as pesticides) are described in better depth than others (such as mining), overall this chapter illustrates the excellent currency of the book, as it touches upon "hot" topics such as climate change legislation.

The next three chapters in Part IV of the text form another meaty section covering environmental impact assessment, land use and resource planning, and economic approaches. Chapter 10 moves from the history of EIA to a comparison of the various approaches to future directions such as strategic assessments and harmonization. The chapter makes good use of charts to compare the various models; while other chapters seek to use visual illustrations to some extent, this is something that could usefully have been expanded throughout the manuscript.

Chapter 11 is one of the longest chapters in the book, looking at the sectoral development of public lands and a series of related sub-issues such as endangered species, parks, and urban planning. Despite its length, the chapter has a strong topic to topic organizational flow and a good emphasis on modern issues (for example, brownfields) and newer approaches. There is an interesting section on energy supply that rather understates the looming challenges, since energy security and climate change are now considered "the greatest global environmental challenge of the 21st century." ${ }^{9}$ It does, however, include some ideas on how to transition to a new pattern of energy usage, with an emphasis on the need for complex decision-making and trade-offs. Hidden away in this chapter is also a good section on the role of municipalities in environmental planning and in solving key issues such as urban sprawl. Indeed, the discussion of municipalities might well have formed a separate chapter, especially since private sector corporations (and the type of voluntary and economic instruments that can be used to influence their behaviour) received separate billing in the final chapter of this Part of the book.

The text moves on in Part V to cover civil litigation, administrative boards, and access to information laws. Chapter 13 describes the use of the courts with a focus on key obstacles to the use of litigation, such as standing and costs. The chapter on administrative tribunals focuses on avenues for public participation in administrative procedures, with a particularly good section on judicial review. The last chapter in the section, chapter 15, tries to focus on other public remedies, beginning with a reasonably clear overview of the "byzantine"10 Ontario Environmental Bill of Rights, $1993^{11}$ and then discussing federal and provincial Access to Information statutes. Given the book's nominal notion of acting as a "citizen's guide," however, it is surprising that other public investigation rights were not surveyed, especially the process for citizen's submissions to the North American Commission for Environmental Cooperation under the North American Free Trade Agreement between the

$9 \quad$ Lakshman Guruswamy, International Environmental Law in a Nutshell, 3d ed. (St. Paul: Thomson West, 2007) at 641.

10 Elaine Hughes, Alastair R. Lucas \& William A. Tilleman, eds., Environmental Law and Policy, 3d ed. (Toronto: Emond Montgomery, 2003) at 445.

S.O. 1993 , c. 28. 
Government of Canada, the Government of the United Mexican States and the Government of the United States of America, ${ }^{12}$ and the role of the federal office of the Auditor General. ${ }^{13}$

Part VI of the text contains a single chapter on the future of environmental law, and it is one of the best chapters in the book. It moves from the past, with a look at the 40 or so years of history of environmental law in Canada, into the future - new and continuing challenges and "the path ahead." "It is easy, in the face of the complexity of environmental problems and continued growth and over-consumption, to despair of making progress on environmental concerns. Nevertheless, as the authors look at where we are today, they are able to maintain a positive tone about many of the "hard-won achievements" to date. ${ }^{15}$ At the same time, they recognize that we are "winning battles but losing the war." ${ }^{16}$ Drawing on past experience, therefore, they seek to identify ten "themes of change" that will shape the direction of future endeavours. These well considered themes are: (1) the increasing scale of the problems; (2) the need for pollution prevention; (3) complexity; (4) the precautionary principle; (5) transparency, participation, and the role of science; (6) globalization; (7) economic efficiency (albeit the authors might have put more emphasis on the polluter pays principle); (8) the roles of governments, NGOs and industry (governance); (9) the "toolbox" or range of approaches; and (10) sustainability, equity, and social justice.

What prescription for change emerges from these themes? An Introduction to Environmental Law and Policy in Canada is not a revolutionary book and contains no dramatic calls to action. Nevertheless, it is completely clear that change is needed, and the authors view the current state of affairs as a "situation exceedingly rich in creative possibilities" rather than as a daunting quagmire. ${ }^{17}$ From this viewpoint, they issue a call to build upon strengths, to share the task with others in fields of study outside of law, and to forge ahead step-by-step toward a "culture of ecological stewardship and social responsibility." 18 Thus, the book is, in the end, a pragmatic book that recognizes the limitations of using law as a tool, and that draws not so much on passion and dramatic activism as it does on a steady resolve to press forward where it makes sense to do so: in situations where the law shows continued potential to help make this world a better place.

\author{
Elaine L. Hughes \\ Professor \\ Faculty of Law \\ University of Alberta
}

17 December 1992, Can. T.S. 1994 No. 2 (entered into force 1 January 1994), described in Boyd, supra note 7 at $216-17$

Office of the Auditor General of Canada, Getting Answers: A Guide to the Environmental Petitions Process (Ottawa: Minister of Public Works and Government Services Canada, 2008), online: Office of the Auditor General <http://www.oag-bvg.gc.ca/internet/docs/pet_lp_e_930.pdf>.

Muldoon et al., supra note 3 at 233.

Ibid. at 224 .

Ibid.

Ibid. at 234 .

Ibid. at 235 . 